\title{
RANCANG BANGUN SCORING BOARD MENGGUNAKAN JOYSTICK BERBASIS ARDUINO YANG DIGUNAKAN PADA LATIH TANDING TAEKWONDO
}

\author{
Komang Agus Werdi Darmayasa ${ }^{1}$, I Gusti Agung Putu Raka Agung ${ }^{2}$, Pratolo \\ Rahardjo $^{3}$ 1,2,3 Prodi Teknik Elektro, Fakultas Teknik, Universitas Udayana \\ Email: aguswerdi666@gmail.com ${ }^{1}$, igapraka@yahoo.co.id ${ }^{2}$, pratolo@unud.ac.id $^{3}$
}

\begin{abstract}
Abstrak
Taekwondo adalah salah satu cabang olahraga beladiri yang dipertandingkan di Olimpiade. Taekwondo berasal dari Korea, Tae berarti "menendang atau menghancurkan dengan kaki"; Kwon berarti "tinju"; dan Do berarti "jalan" atau "seni". Pertandingan taekwondo dipimpin oleh seorang wasit dan juri yang bertugas memberikan nilai kepada atlet yang mendapat poin. Pada saat latih tanding taekwondo, penilaian masih dilakukan dengan cara yang manual sehingga diperlukan peralatan skor elektronik yang portable dan mudah dioprasikan. Berdasarkan hal tersebut, maka ada suatu keinginan untuk membuat peralatan skor elektronik yang digunakan untuk latih tanding taekwondo yaitu dengan membuat alat scoring board menggunakan Joystick berbasis Arduino. Pada alat scoring board berbasis arduino ini menggunakan dua buah stick ps3 yang dihubungkan ke arduino secara wireless menggunakan Bluetooth dan diterima oleh reciver joystick. Tampilan nilai dari latih tanding ini akan ditampilkan pada display LED Matrix berupa angka/skor. Waktu dan ronde latih tanding taekwondo ditampilkan pada display seven segment dan disetting pada awal latih tanding menggunakanjoystick yang berwarna biru. Pada saat waktu pertandingan habis, akan ada bunyi yang dikeluarkanoleh buzzer.Dari penelitian yang dilakukan, diharapkan mampu mempermudah penilaian saat latih tanding taekwondo.
\end{abstract}

Kata kunci: Arduino, Joystick, Taekwondo

\begin{abstract}
Taekwondo is one of the martial arts competitions competed in the Olympics. Taekwondo comes from Korea, Tae means "kicking or destroying with legs"; Kwon means "boxing"; and Do means "road" or "art". The taekwondo match is led by a referee and a judge who is responsible for giving scores to athletes who get points. During taekwondo match training, the assessment is still done in a manual way so that electronic score equipment is needed that is portable and easy to operate. Based on this, there is a desire to make electronic score equipment used for taekwondo match training by creating a scoring board using an Arduino-based joystick. The Arduino-based scoring board uses two PS3 sticks that are connected to Arduino wirelessly using Bluetooth and received by the joystick receiver. The display value of this match training will be displayed on the LED Matrix display in the form of numbers / scores. The time and the taekwondo match training round are displayed on the seven segment display and are set at the beginning of the practice match using a blue joystick. When the match time runs out, there will be a sound issued by the buzzer. From the research conducted, it is expected to be able to facilitate assessment when competing in taekwondo training.
\end{abstract}

Keywords: Arduino, Joystick, Taekwondo, 


\section{$J$.}

\section{PENDAHULUAN}

Taekwondo adalah salah satu cabang olahraga beladiri yang dipertandingkan di Olimpiade. Taekwondo berasal dari Korea, Tae berarti "menendang atau menghancurkan dengan kaki"; Kwon berarti "tinju"; dan Do berarti "jalan" atau "seni". Jadi, Taekwondo dapat diterjemahkan dengan bebas sebagai "seni tangan dan kaki" atau "jalan" atau "cara kaki dan kepalan".Pertandingan taekwondo dipimpin oleh seorang wasit dan empat juri yang bertugas memberikan nilai kepada atlet yang mendapat poin.

Rumusan masalah pada penelitian ini adalah bagaimana merancang dan membuat peralatan scoring board untuk system penjurian pada latih tanding taekwondo berbasis Arduino.

Tujuan penelitian ini adalah dapat merancang dan membuat alat scoring board berbasis Arduino yang layak digunakan untuk penjurian pada latih tanding taekwondo.

\section{Kajian Pustaka}

Alat yang akan dirancang pada penelitian ini adalah alat scoring board menggunakan Seven Segment dan LED Matrix sebagai tampilannya. Dalam pembuatan alat ini digunakan joystick berbasis Arduino. Pada joystick ada empat tombol yang digunakan untuk team biru dan empat tombol untuk team merah. Jika salah satu tombol ditekan oleh juri maka data dari joystick akan diolah di Arduino dan ditampilkan pada Sevent Segmen. Penelitian - penelitian sebelumnya yang terkait dengan penelitian ini adalah, sebagai berikut :

1. Khaerudin, dkk (2008) membuat sistem scoring counter menggunakan joystick berbasis PPI 8255 dengan pemrograman Delphi [ 1 ].

2. Andika Muharam, dkk (2008) membuat sistem pengendali papan skor kejuaraan beladiri taekwondo berbasis mikrokontroler AT89S52 [ 2 ].

\subsection{Sejarah Taekwondo}

Taekwondo telah dikembangkan selama 5000 tahun sejarah korea dengan penyebutan yang beragam. Di Korea taekwondo awalnya dikenal sebagai seni beladiri yang disebut "Subak" atau "Taekkyon" dan dikembangkan sebagai cara untuk melatih tubuh dan pikiran dalam masa kerajaan kuno dari Koguryo dengan nama Sunbae. Pada masa Shila, ini menjadi tulang punggung dari Hwarangdo yang bertujuan untuk mengkader pemimpin-pemimpin negeri.

\subsection{Arduino Uno}

Arduino UNO adalah sebuah board mikrokontroler yang didasarkan pada ATmega328. Arduino UNO mempunyai 14 pin digital input/output (6 di antaranya dapat digunakan sebagai output PWM), 6 input analog, sebuah osilator Kristal 16 $\mathrm{MHz}$, sebuah koneksi USB, sebuah power jack, sebuah ICSP header, dan sebuat tombol reset. Arduino UNO memuat semua yang dibutuhkan untuk menunjang mikrokontroler,mudah menghubungkannya ke sebuah computer dengan sebuah kabel USB atau mensuplainya dengan sebuah adaptor AC ke DC atau menggunakan baterai untuk memulainya. Gambar 1 menunjukan board arduino uno.

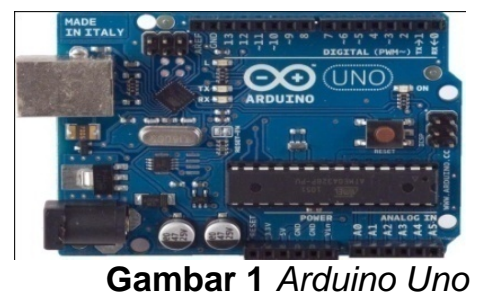

\subsection{Joystick}

Joystick adalah alat masukan komputer yang berwujud tuas yang dapat bergerak ke segala arah. Alat ini dapat mengirim sinyal arah sebesar dua atau tiga dimensi ke komputer. Alat ini umumnya digunakan sebagai pelengkap untuk memainkan permainan video yang dilengkapi lebih dari satu tombol. Tampilan Joystick ditunjukkan padagambar 2 . 


\section{$J$.}

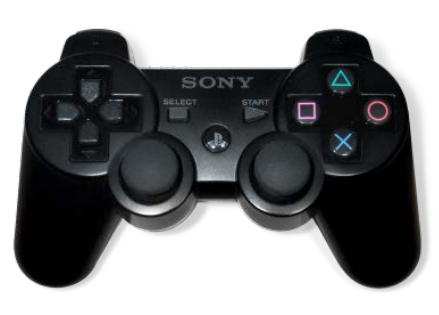

Gambar 2 Joystick Ps3.

\section{METODE PENELITIAN}

\subsection{Perancangan Perangkat Scoring Board menggunakan Joystick berbasis Arduino}

Pelaksanaan penelitian Scoring Counter ini dilakukan di Laboratorium Dasar Teknik Digital dan Mikro Prodi Teknik Elektro Fakultas Teknik, Universitas Udayana, Bukit Jimbaran. Pada metode perancangan scoring board menggunakan joystick berbasis Arduino dibagi menjadi perancangan hardware dan software. Perancangan perangkat keras (hardware) pada pembuatan alat Scoring Counter berbasis Arduino menggunakan program Eagle 5.6.0 dan terlebih dahuludisimulasikan pada program Proteous. Perancangan perangkat keras meliputi perangkat keras sebagai berikut :

1. Perancangan Arduino Uno. Board Arduinoberfungsi sebagai pengolah data pada rangkaian Scoring Counter menggunakan Joystick. Board ini membutuhkan tegangan input $5 V_{D C}$. Rangkaian Arduinoadalah komponen utama dari rancang bangun Scoring Counter menggunakan Joystick, karena pada rangkaian ini memproses input dari joystickdan menghasilkan keluaran berupa tampilan pada Seven Segment.

2. Perancangan Rangkaian Joystick.Rangkaian Joystick ini berfungsi sebagai input data ke Arduino. Pada Rangkaian Scoring Counter menggunakan Joystick berbasis Arduino ini menggunakan 2 joystick dan pada masing - masing joystick digunakan 4 tombol untuk team merah dan 4 tombol untuk team biru.

3. Perancangan rangkaian Speaker. Rangkaian speaker berfungsi sebagai indikator ketika waktu pertandingan atau latihan Taekwondo telah habis. Speaker yang digunakan adalah speaker DC yang memerlukan tegangan input sebesar $5 V_{D C}$. Speaker ini dilengkapi dengan transistor BC547A dan BD139. Speaker menggunakan penguat transistor yang disusun secara darlington.

4. Perancangan rangkaian sevent segmen. Rangkaian Seven Segment berfungsi sebagai output data pada rangkaian Scoring Board berbasis. Seven Segment yang dipakai pada alat ini adalah Seven Segment common anoda. Rangkaian Seven Segment ini akan berfungsi jika mendapat input data dari Arduino.

5. Perancangan perangkat lunak (Software)dalam

mengimplementasikan Scoring Board menggunakan Joystick berbasis Arduinomenggunakan software arduino 1.0.6 dengan bahasa pemrograman $C$. Software ini hampir sama dengan IDE (Intergrated Development Environment) yang lain, Arduino 1.0.6 dilengkapi dengan sourcecodeeditor, compiler, dan banyak terdapat contoh program untuk memudahkan pemrograman hardware.

\subsection{Flochart Program}

Flochart Program/ perangkat lunak ini ditunjukkan pada gambar 3 
$J$.

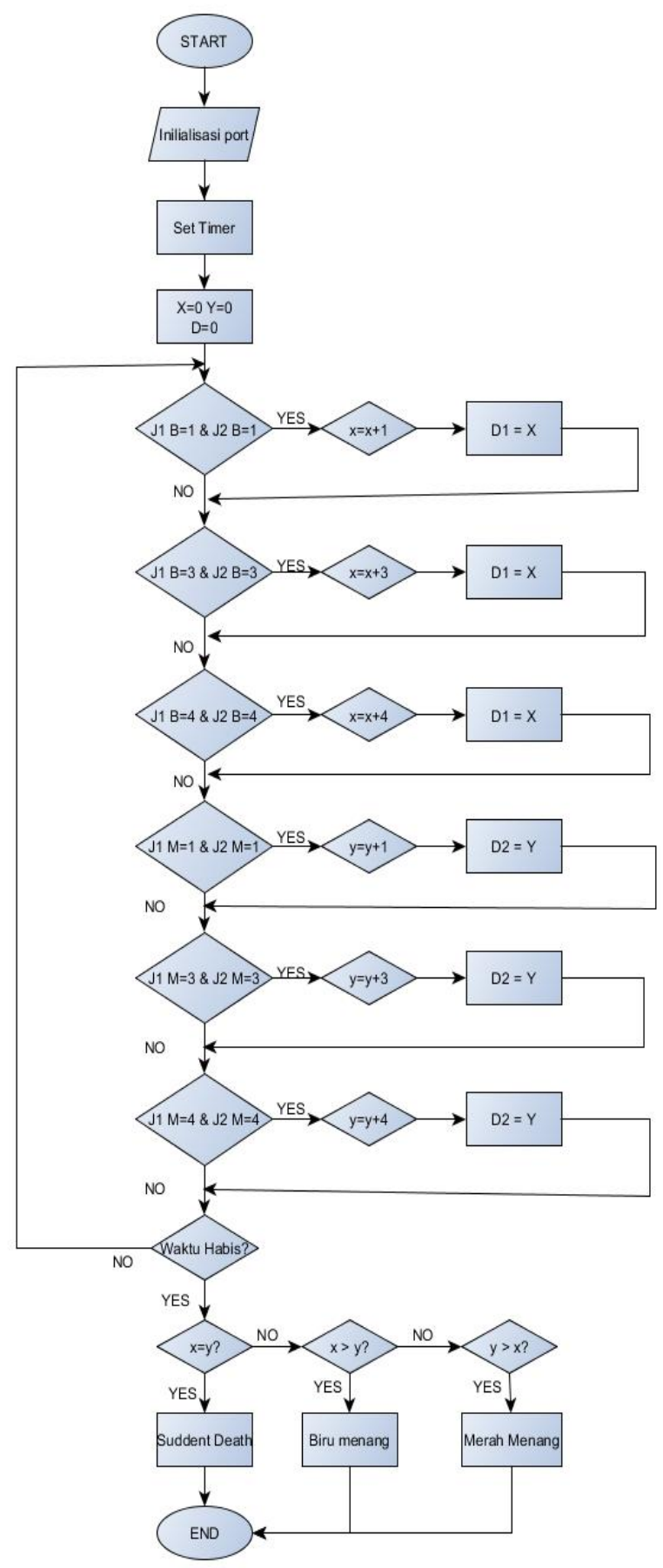

Gambar 3Diagram Alir (Flowchart) Program

\section{HASIL DAN PEMBAHASAN}

\subsection{Realisasi Hasil Perancangan Alat.}

Alat Scoring Board Menggunakan Joystick Berbasis Arduino spesifikasi antara lain tinggi alat $67 \mathrm{~cm}$, panjang alat $130 \mathrm{~cm}$, power supply adaptor $12 \mathrm{v}, 2$ reciver joystick, 1 arduino. Gambar 4 menunjukan tampilan alat Scoring Board menggunakan Joystick berbasis Arduino.

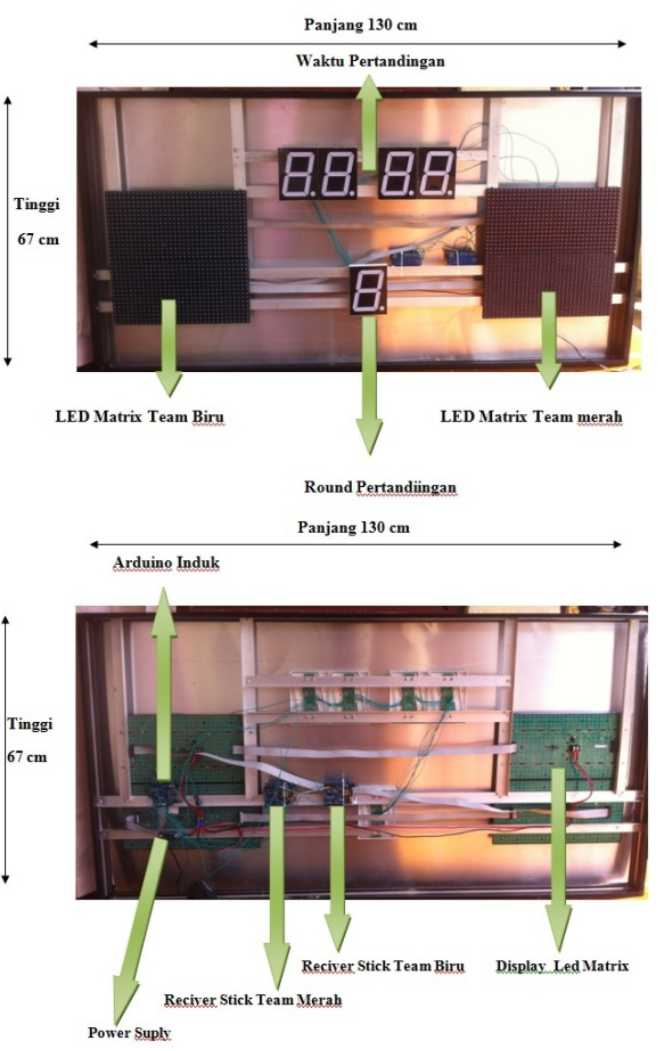

Gambar 4. Realisasi Alat Scoring Board Menggunakan Joystick Berbasis Arduino.

\subsection{Pengujian dan Pembahasan Hasil Perancangan Scoring Board TaekwondoBerbasis Arduino}

Alat Scoring Board ini terdiri dari beberapa rangkaian. Pengujian dilakukan pada setiap rangkaian yang telah direalisasikan. Adapun perangkat yang akan diuji adalah sebagai berikut : 
$J$.

\subsubsection{Pengujian Sistem Minimum Arduino}

Pengujian dan pembahasan mengenai sistem minimum Arduino untuk mengetahui sistem minimum Arduino bekerja dengan baik. Adapun diagram blok dari pengujian pengiriman data program ke dalam Chipmikrokontroler ATmega328 sebagai mikrokontroler ATmega328 dapat dilihat pada gambar 5

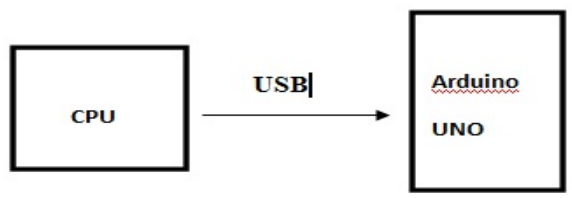

Gambar 5. Diagram blok pengujian pengiriman data mikrokontroler.

Dari diagram blok pada Gambar 5 dapat dijelaskan bahwa proses pengujian ini menggunakan USB untuk mengirim data ke dalam Chip mikrokontroler.

Sebelum melakukan pengujian terlebih dahulu membuka tab serialmonitor yang terdapat pada software arduino 1.0.6. Setelah itu dilakukan koneksi maka pada Serial Monitor Arduinoakan tampil data yang dikirim oleh mikrokontroler sesuai program yang kita masukkan pada Arduino. Tampilan Serial Monitor yang diperoleh saat pertama kali program dijalankan seperti pada Gambar 6.

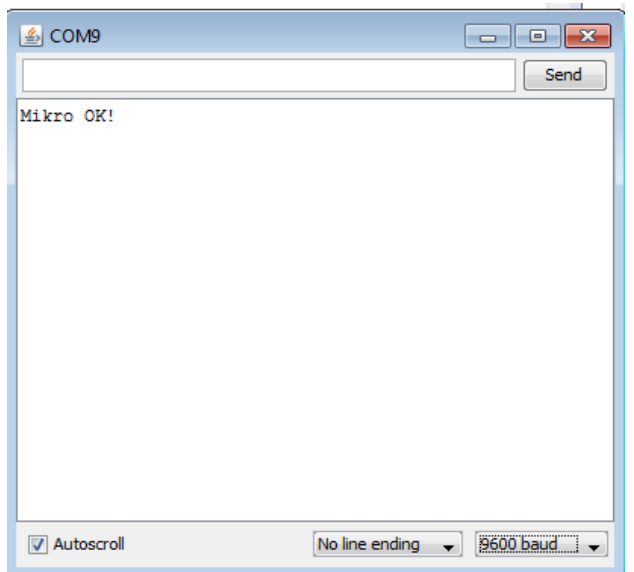

Gambar 6. Hasil Pengujian Pengiriman Data Mikrokontroler ATmega328

\subsubsection{Pengujian Rangkaian Receiver Joystick}

Alat Scoring Board menggunakan Receiver Joystick sebagai penerima data yang dikirim dari Joystick. Tujuan dari pengujian rangkaian receiver ini adalah untuk mengetahui apakah rangkaian receiver yang dirancang dapat berfungsi sesuai dengan yang telah direncanakan. Diagram blok pengujian Receiver Joystick dapat dilihat pada Gambar7.

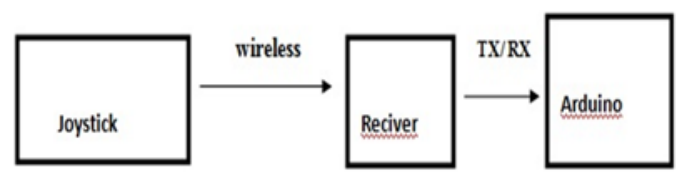

Gambar 7. Diagram blok reciver joystick

Dari diagram blok pada Gambar 7 dapat dijelaskan bahwa, proses pengiriman data dari joystick ke receiver ini menggunakan wirelesss bluetooth. Sedangan proses pengiriman data dari receiver ke arduino melalui pin TX, RX. Receiver pada gambar 7 berfungsi untuk menerima perintah dari joystick dan akan dikirimkan ke arduino. Pada pengujian reciver joysticktersebut dibuat dengan menggunakan bahasa $\mathrm{C}$ dengan software Arduino 1.0.6.

\subsubsection{Pengujian Rangkaian Seven Segment}

Berikut ini merupakan pengujian yang dilakukan pada sensor rangkaian sevent segmen untuk mengetahui apakah rangkaian tersebut bekerja sesuai keinginan. Adapun diagram blok pengujian dari rangkaian seven segmentsebagai berikut :

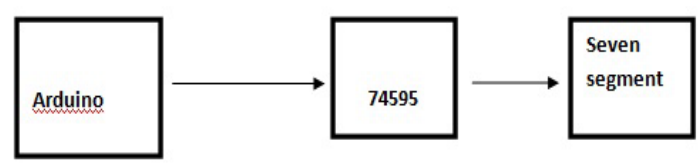

Gambar 8. Diagram blok rangkaian seven segment 
$J$.

Dari diagram blok pada Gambar 8 dapat dijelaskan bahwa, data yang dikirimkan dari arduino akan dikirim ke ic 74595 kemudian dikirim ke seven segment. Ketika listing program telah ditransfer ke arduino, maka seven segment akan menampilkan display sesuai perintah. Gambar 9 menunjukkan hasil dari pengujian seven segment.

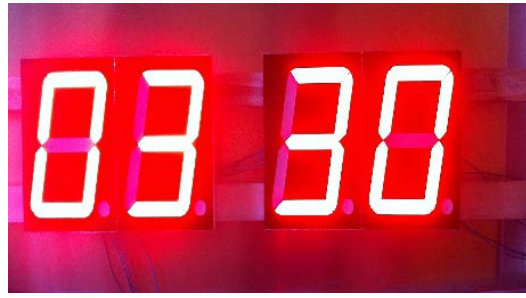

Gambar 9. Tampilan hasil pengujian seven segment

\subsubsection{Pengujian Keseluruhan Sistem Scoring Board Menggunakan Joystick Berbasis Arduino}

Pengujian keseluruhan peralatanScoring Board Menggunakan Joystick Berbasis Arduino bertujuan untuk mengetahui apakah alat tersebut mampu bekerja dengan baik. Pengujian keseluruahan alat ini menggunakan dua buah stick ps 3 dan dilakukan saat latih tanding taekwondo. Tampilan keseluruhan alat scoring board dapat dilihat pada gambar 9 .

\section{Q0}
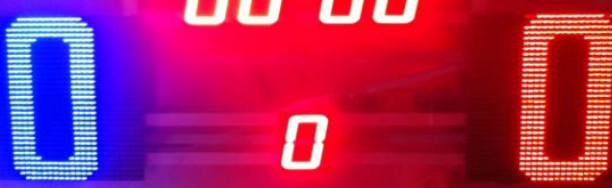

Gambar 10. Tampilan keseluruhan scoring board.

Cara kerja alat ini adalah ketika alat ini dihidupkan maka tampilan di display berubah menjadi nol, selanjutnya untuk mengatur waktu pertandingan dan rounde tekan tombol select pada stick biru. Setelah mengatur waktu pertandingan selanjutnya tekan tombol start untuk memulai pertandingan atau memberi scor pada masing - masing team.

\subsubsection{Mengatur Waktu Pertandingan Pada Alat Scoring Board Taekwondo}

Gambar 10 dan 11 menunjukkan cara mengatur waktu pertandingan pada alat scoring board taekwondo.

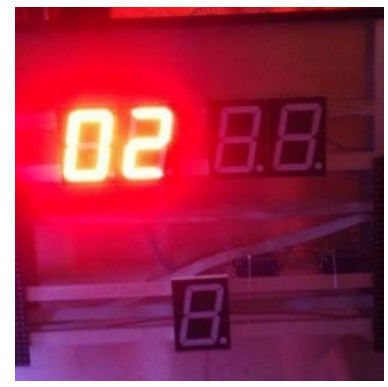

Gambar 11Tampilan pada saat mengatur waktu pertandingan

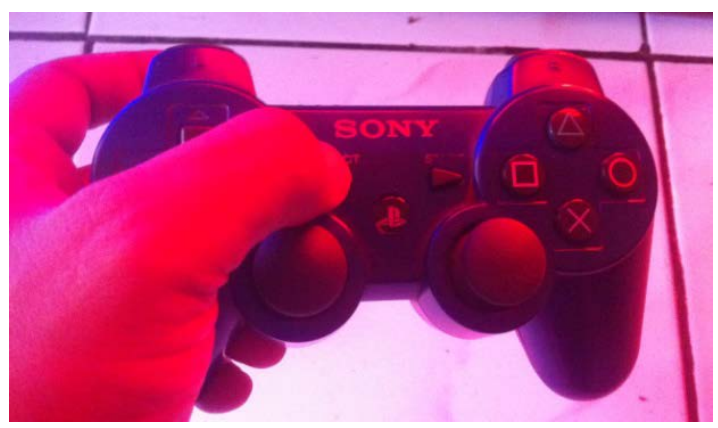

Gambar 12Tampilan pada saat menekan tombol select

Pada gambar 10 dan 11 terlihat cara untuk mengatur waktu pertandingan pada saat latih tanding taekwondo adalah dengan cara menekan tombol slect pada stick biru seperti pada gambar 11 . Setelah itu atur waktu pertandingan sesuai yang dibutuhkan.

\subsubsection{Mengatur Ronde Pertandingan Pada Alat Scoring Board Taekwondo \\ Gambar 12dan 13 menunjukkan cara mengatur rounde pertandingan pada alat scoring board taekwondo.}


$J$.

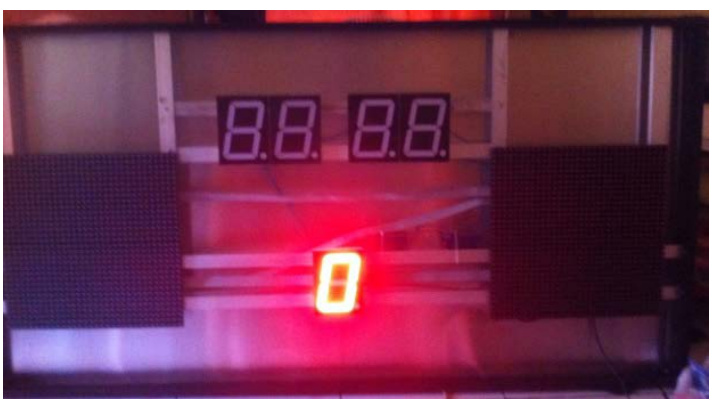

Gambar 13Tampilan pada saat mengatur ronde pertandingan

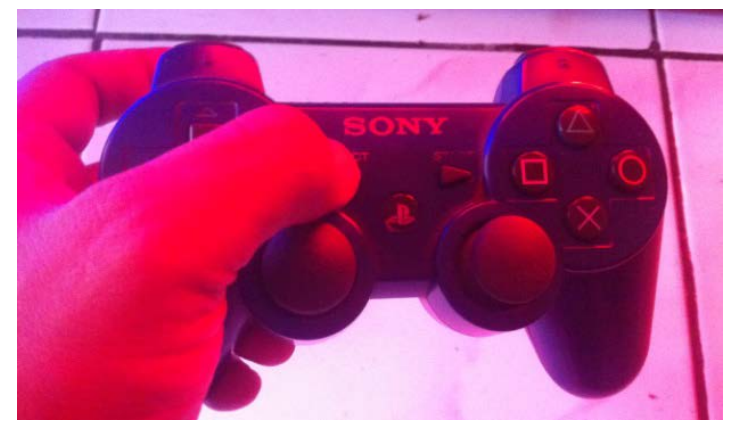

Gambar 14Tampilan pada saat menekan tombol select

Pada gambar 12 dan 13 terlihat cara untuk mengatur waktu pertandingan pada saat latih tanding taekwondo adalah dengan cara menekan tombol select pada stick biru seperti pada gambar 13 Sama seperti cara mengatur waktu cuma bedanya saat menekan tombol select pada pengaturan rounde tombol select ditekan 3 kali.

\subsubsection{Tampilan Pada Alat Scoring Board Taekwondo Pada Saat Pertandingan Selesai}

Pada saat pertandingan selesai maka tampilan waktu pada seven segment akan berubah jadi nol. Sedangkantampilan scor tidak akan berubah menjadi nol. Pada saat waktu habis ada nada bunyi buzzer yang menandai waktu pertandingan telah habis. Gambar 14 menunjukkan tampilan scoring board taekwondo pada saat waktu habis.

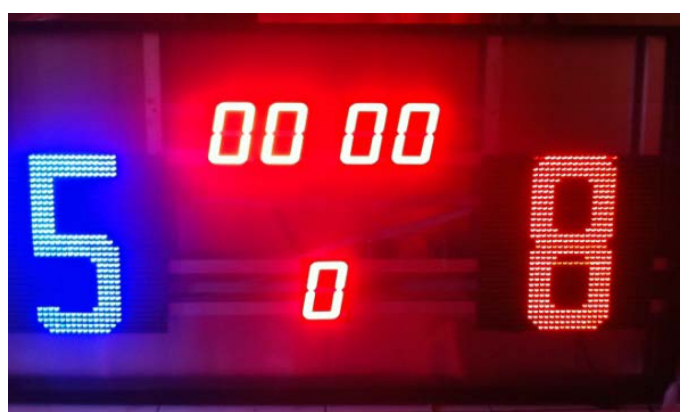

Gambar 15Tampilan pada saat waktu pertandingan habis

\section{SIMPULAN}

Berdasarkan dari hasil penelitian ini dapat disimpulkan bahwa Alat Scoring Board menggunakan Joystick berbasis Arduinoyang digunakan pada latih tanding Taekwondo sudah dapat diimplementasikan dengan menggunakanJoysticksebagai input data danLED Matrix / Seven Segmentsebagaidisplay output data.

\section{DAFTAR PUSTAKA}

[1] Khaerudin. (2008) membuat sistem scoring counter menggunakan joystick berbasis PPI 8255 dengan pemrograman Delphi.

[2] Andika Muharam. (2008) sistem pengendali papan skor kejuaraan beladiri taekwondo berbasis mikrokontroler AT89S52.

[3] Dadang Krisdayadi, H. Suryana P. (2004). Teknik Dasar, Poomsae, dan Peraturan Pertandingan. Jakarta : Gramedia Pustaka Utama

[4] Ikapuspad. (2009) Penilaian dalam pertandingan Taekwondo.

[5] V. Yoyok Suryadi. (2013) Poomsae Taekwondo untuk kompotisi. Jakarta : Gramedia Pustaka Utama. 